\title{
Systemic mastocytosis involving the gastrointestinal tract: clinicopathologic and molecular study of five cases
}

Richard Kirsch ${ }^{1}$, Karel Geboes ${ }^{2}$, Neil A Shepherd ${ }^{3,4}$, Gert de Hertogh ${ }^{2}$, Nando Di Nicola ${ }^{1}$, Sylvie Lebel ${ }^{5}$, Ugnius Mickys ${ }^{6}$ and Robert H Riddell ${ }^{1}$

${ }^{1}$ Department of Pathology and Laboratory Medicine, Mount Sinai Hospital, University of Toronto, Toronto, ON, Canada; ${ }^{2}$ Department of Pathology, University Hospital Leuven, Leuven, Belgium; ${ }^{3}$ Department of Histopathology, Gloucestershire Royal Hospital, Gloucester, UK; ${ }^{4}$ Cranfield Postgraduate Medical School in Gloucestershire, Gloucestershire Royal Hospital, Gloucester, UK; ${ }^{5}$ Department of Gastroenterology, Children's Hospital of Los Angeles, the Keck School of Medicine of University of Southern California, Los Angeles, CA, USA and ${ }^{6}$ National Center of Pathology, Vilnius, Lithuania

\begin{abstract}
Systemic mastocytosis is an uncommon condition characterized by abnormal proliferation of mast cells in one or more organ. The specific D816V KIT mutation is present in most cases. Gastrointestinal symptoms occur commonly but histologic characterization of gastrointestinal involvement is incomplete. The purpose of this study was (1) to describe the clinicopathologic features in five patients with systemic mastocytosis involving the gastrointestinal tract and (2) to determine whether gastrointestinal involvement is associated with the usual D816V mutation or a different mutation. Clinical details were obtained from the hospital of origin or referring pathologist. Histologic features were documented in slides stained with hematoxylin and eosin, mast cell tryptase and CD117. Molecular analysis for the D816V KIT mutation was performed on formalin-fixed paraffinembedded sections. Symptoms included diarrhea/loose stools $(n=5)$, abdominal pain $(n=4)$, vomiting $(n=3)$ and weight loss $(n=3)$. Other findings included cutaneous lesions of mastocytosis $(n=4)$, malabsorption $(n=2)$, hypoalbuminemia $(n=2)$ and constitutional growth delay $(n=1)$. Sites of gastrointestinal involvement included the colon $(n=5)$, duodenum $(n=3)$ and terminal ileum $(n=3)$. Endoscopic/gross findings included mucosal nodularity $(n=4)$, erosions $(n=2)$ and loss of mucosal folds $(n=2)$. In three patients the endoscopic appearance was considered consistent with inflammatory bowel disease. All cases showed increased mast cell infiltration of the lamina propria, confirmed by immunohistochemistry for mast cell tryptase and CD117. In two cases, mast cells had abundant clear cytoplasmic resembling histiocytes. Marked eosinophil infiltrates were present in four patients, in one patient leading to confusion with eosinophilic colitis. Architectural distortion was noted in three cases. The D816V KIT mutation was present in all four cases tested. In conclusion, gastrointestinal involvement by systemic mastocytosis is characterized by a spectrum of morphologic features that can be mistaken for inflammatory bowel disease, eosinophilic colitis or histiocytic infiltrates. Systemic mastocytosis involving the gastrointestinal tract is associated with the usual D816V KIT mutation.
\end{abstract}

Modern Pathology (2008) 21, 1508-1516; doi:10.1038/modpathol.2008.158; published online 17 October 2008

Keywords: Systemic mastocytosis; gastrointestinal; mast cell; pathology; D816V

Mastocytosis is an uncommon condition characterized by an abnormal proliferation of mast cells in one or more organ. The vast majority of cases are confined to the skin (urticaria pigmentosa) but

Correspondence: Dr R Kirsch, MBChB, PhD, FRCPC, Department of Pathology and Laboratory Medicine, Mount Sinai Hospital, 600 University Avenue, Toronto, ON M5G 1X5, Canada.

E-mail: rkirsch@mtsinai.on.ca

Received 15 April 2008; revised 18 June 2008; accepted 19 June 2008; published online 17 October 2008 approximately $10 \%$ involve extracutaneous sites, most commonly bone, liver, spleen, gastrointestinal tract and lymph nodes. Over $90 \%$ of patients with systemic mastocytosis exhibit the D816V KIT mutation in lesional tissue. ${ }^{1}$ Gastrointestinal symptoms are second only to pruritis as the major cause of morbidity in these patients. The reported rates of gastrointestinal symptoms in systemic mastocytosis have varied considerably, but most recent studies report gastrointestinal symptoms in 60$80 \%$ of patients with systemic mastocytosis. Such 
symptoms include abdominal pain (dyspeptic and non-dyspeptic), nausea, vomiting and diarrhea. ${ }^{2}$ Increased systemic levels of mast cell mediators (eg histamine, leukotrienes, heparin and proteases) are likely to be important in the genesis of gastrointestinal symptoms, since not all symptomatic patients have increased numbers gastrointestinal mucosal mast cells. ${ }^{3}$ Direct involvement of the gastrointestinal tract by neoplastic mast cells has been documented in small series and case reports, ${ }^{3-23}$ but the histopathologic spectrum of gastrointestinal tract mastocytosis is incompletely characterized. This series of five patients with gastrointestinal involvement by mastocytosis and review of the literature documents the clinical and morphologic spectrum of gastrointestinal involvement by systemic mastocytosis, highlights potential difficulties and pitfalls associated with this diagnosis, and evaluates these patients for the presence of the D816V KIT mutation.

\section{Materials and methods}

Five cases of systemic mastocytosis involving the gastrointestinal tract were retrieved from the consultation files of three gastrointestinal pathologists (KG, RHR, NAS). One of the cases was previously published in case report form. ${ }^{24}$ Clinical details were obtained from chart review or from the referring pathologist or gastroenterologist. Histologic features were documented in slides stained with hematoxylin and eosin, mast cell tryptase and CD117. Molecular analysis for the D816V KIT mutation was performed on all cases in which archival material was available (4 of 5 cases). Direct sequencing of exon 17 of the c-kit gene was performed initially and this was followed by enriched sequencing of mutant alleles ${ }^{25}$ in cases that were negative.

\section{Direct Sequencing of PCKIT-17}

Direct sequencing was performed on formalin-fixed paraffin-embedded tissue in three cases and on fresh bone marrow tissue in the fourth. Before performing the sequencing reactions, $10-100 \mathrm{ng}$ DNA in a total volume of $50 \mu \mathrm{l}$ containing $2 \mathrm{ng} / \mu \mathrm{l}$ of each primer PCKIT-17F and PCKIT-17R, $3 \mathrm{mmol} / \mathrm{l} \quad \mathrm{MgCl}_{2}$, $0.2 \mathrm{mmol} / \mathrm{l}$ each dNTPs, $0.02 \mathrm{U}$ of Platinum Taq DNA Polymerase (Invitrogen, Carlsbad, CA, USA) and $1 \times$ buffer was amplified. After an initial DNA polymerase activation step $\left(95^{\circ} \mathrm{C}\right.$ for $\left.4 \mathrm{~min}\right), 40$ cycles of $94^{\circ} \mathrm{C}$ for $30 \mathrm{~s} / 58^{\circ} \mathrm{C} 30 \mathrm{~s} / 72^{\circ} \mathrm{C} 30 \mathrm{~s}$ were performed, with a final $72^{\circ} \mathrm{C}$ extension of $10 \mathrm{~min}$. The 416-bp products obtained were visualized on a $2 \%$ agarose gel stained with ethidium bromide.

Obtained products $(5 \mu \mathrm{l})$, enzymatically purified using EXO-SAP-IT (USB, Cleveland, Ohio, USA) according to manufacturer's instructions, were then used as a template for the cycle sequencing reaction. Sequencing reactions were performed using BDT version 1.1 Chemistry (Applied Biosytems, CA, USA), as stated by the manufacturer. Briefly, $5 \mu \mathrm{l}$ of purified product, $2.0 \mu \mathrm{l}$ of $5 \times$ sequencing buffer, $1.0 \mu \mathrm{l}$ each of Ex17F or Ex17R primer $(100 \mathrm{ng} / \mu \mathrm{l})$ and $14 \mu \mathrm{l}$ of $\mathrm{dH}_{2} \mathrm{O}$. The cycling conditions were $95^{\circ} \mathrm{C}$ for $10 \mathrm{~min}$ followed by 25 cycles of $95^{\circ} \mathrm{C}$ for $10 \mathrm{~s} / 56^{\circ} \mathrm{C}$ $5 \mathrm{~s} / 60^{\circ} \mathrm{C} 3 \mathrm{~min}$. After cycle sequencing, products were purified with Sephadex G-50 Fine (GE Healthcare, Sweden) and analyzed on an ABI 3130xl (Foster City, CA, USA).

\section{Enriched Sequencing of Mutant Alleles}

To reduce the number of normal alleles relative to variant alleles, $10 \mu \mathrm{l}$ of the 416-bp PCR product was digested with 7.5 U of BSMAI (New England Biolabs Ltd., Pickering, ON, Canada) for $3 \mathrm{~h}$ at $55^{\circ} \mathrm{C}$ and visualized on an ethidium-stained agarose gel. BSMAI recognizes GANAC in normal DNA, generating three products, 184, 160 and $72 \mathrm{bp}$. In DNA carrying the D816V mutant, the BSMAI recognition site is lost and (GANTC) leaving one cut site generating a $184 \mathrm{bp}$ fragment and a $232 \mathrm{bp}$ fragment. The latter was excised from the agarose and purified with QIAquick Gel Extraction Kit (Qiagen, Mississauga, ON, Canada) and subjected to a second round of seminested PCR reaction as previously described..$^{25}$ The PCR sequencing conditions were the same as described for the exon 17 pre-sequencing PCR reaction except that the forward primer BSMAI was used. The product, enriched for the mutant allele, was then analyzed by sequencing.

\section{Primers}

Predigest: P-CKIT-17F, 5'-TATGTGAACATCATTC AAGGCG-3'; P-CKIT-17R, 5'-TGTGTGATATCCCTAG ACAGG-3'; post-digest: BSMAI_F, 5'-TTGGCAGCC AGAAATATCCTC- $3^{\prime}{ }^{25}$

\section{Results}

\section{Clinical Features}

The age range was 12-55 years (median, 38 years). All patients were women. The duration of symptoms was $0.5-5$ years. The symptoms included diarrhea/loose stools $(n=5)$, abdominal pain $(n=4)$ (frequently cramping, $n=3$ and postprandial, $n=3)$, loss of weight $(n=4)$ and vomiting $(n=3)$. Other findings included cutaneous lesions of mastocytosis $(n=4$; one of the four patients developed skin lesions only subsequent to diagnosis of systemic mastocytosis on gastrointestinal biopsies), malabsorption $(n=2)$, hypoalbuminemia $(n=2)$ and constitutional growth delay $(n=1)$. 



Figure 1 (a) Subtotal colectomy specimen from a patient with both systemic mastocytosis and ulcerative colitis. The distal twothirds of the colonic mucosa show features characteristic of ulcerative colitis including a flat mucosa (distal third) and diffuse mucosal granularity (middle third). The proximal third shows a distinctive mucosal nodularity. (b) Detail of proximal colon showing distinctive nodularity. (c) Endoscopy of duodenum in a patient with systemic mastocytosis showing loss of mucosal folds and a mucosal nodularity.

\section{Endoscopic and Macroscopic Findings}

Five patients underwent colonoscopy and four patients underwent gastroduodenoscopy. The documented sites of gastrointestinal involvement were the colon $(n=5)$, terminal ileum $(n=3)$ and duodenum $(n=3)$. Findings at each specific site were as follows: colon: nodularity $(n=3)$, pseudopolyps $(n=2)$, aphthous ulcers, erosions, granularity, loss of folds, erythema, edema, punctate hemorrhages, no abnormality (all, $n=1$ ). Terminal ileum: nodularity $(n=2)$, erosion, loss of folds, edema, no abnormality (all, $n=1$ ). Stomach: thickened gastric folds $(n=3)$; no abnormality $(n=1)$. Duodenum: erosion $(n=3)$, nodularity, thickened folds, friability (all, $n=1$ ). Overall, the most frequent and characteristic finding was that of mucosal nodularity $(n=4)$. The mucosal nodules ranged from $1 \mathrm{~mm}$ to several millimeters in size (Figure 1).

In three patients, the endoscopic findings were initially considered consistent with inflammatory bowel disease; one patient had coexisting ulcerative colitis. This patient underwent a subtotal colectomy for longstanding ulcerative colitis (Figure 1a and b). The colon showed two distinct appearances, the distal two-thirds showing features characteristic of ulcerative colitis including a flat mucosa (distal third) and diffuse mucosal granularity (middle third) while the proximal third showed distinctive mucosal nodularity as described above.

\section{Histologic Findings}

All cases showed mast cell infiltration of the lamina propria that was dense in four cases. In the latter, the lamina propria was expanded by mast cells arranged in sheets, aggregates and prominent pericryptal concentric whorls (Figure 2a-d). Four cases were associated with a marked eosinophil infiltrate, which in areas overshadowed the mast cell infiltrate (Figure 2e and f). Four cases showed mild to moderate disturbance of the mucosal architecture (one of these patients had coexistent ulcerative colitis). Architectural changes in the small bowel included broadening and flattening of villi whilst those in the large bowel included irregularity in crypt shape, size and spacing (Figure 2g). A patchy, mixed infiltrate including lymphocytes and plasma cells was present in most cases (Figure 2h). The mast cells showed a range of morphological appearances that included small round cells resembling normal mast cells (Figure 3a), elongated or spindleshaped cells (Figure 3b), plump or fusiform cells with pale eosinophilic cytoplasm (Figure 3c) and large, round cells with abundant pale to clear cytoplasm, the latter a result of retraction artifact (Figure 3d). The latter two patterns strongly resembled histiocytic infiltrates. A combination of histochemical stains (Giemsa and Leder), immunohistochemical stains (mast cell tryptase and CD117) 

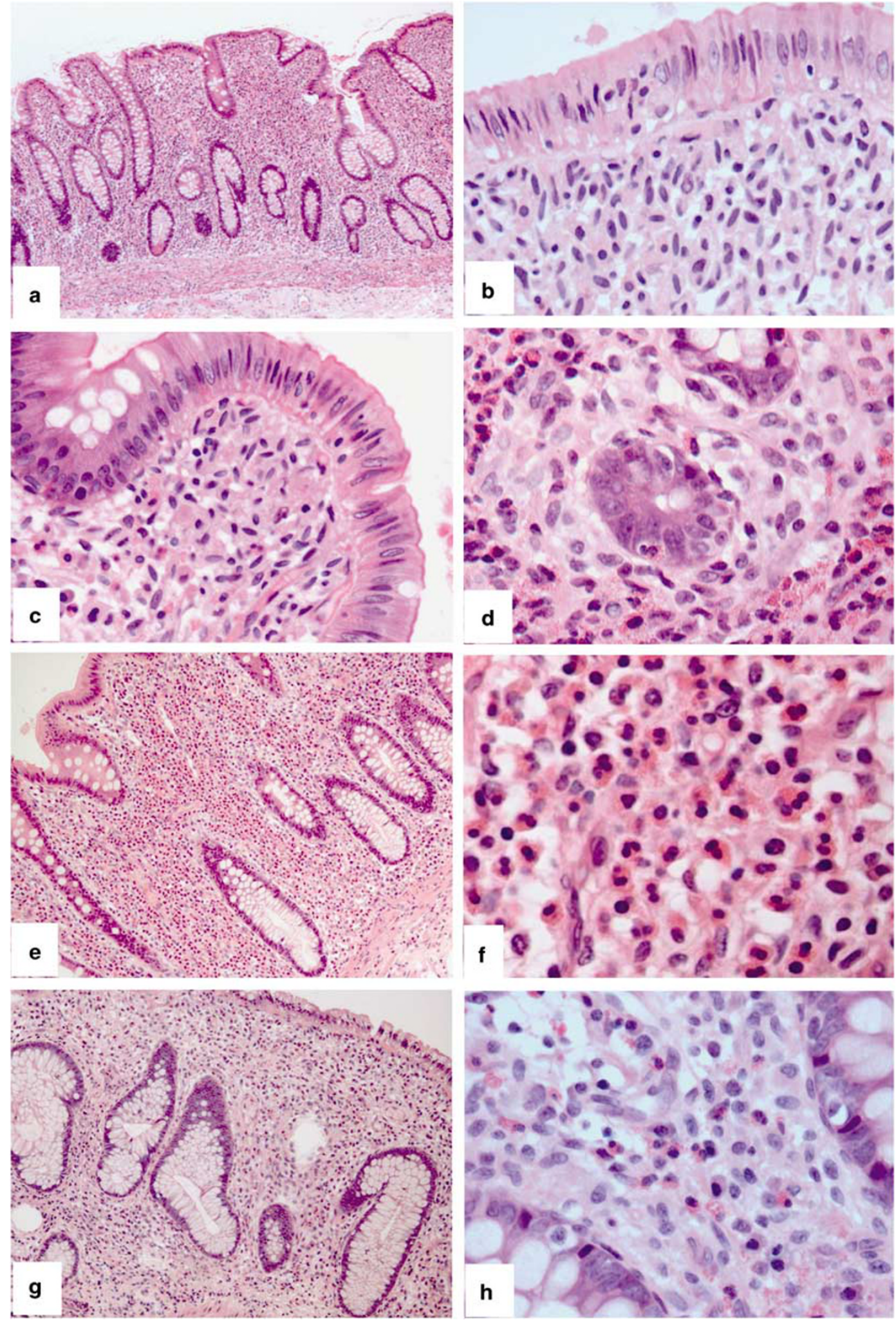

Figure 2 Spectrum of histologic findings in patients with intestinal involvement by systemic mastocytosis. (a) Section from the region illustrated in Figure 1b showing expansion of the lamina propria by a cellular infiltrate. Higher magnification micrographs (b-d) show this infiltrate to be composed of mast cells arranged in sheets (b), aggregates (c) or in characteristic pericryptal whorls (d). A heavy eosinophil infiltrate frequently dominated the picture and at times obscured the underlying mast cell infiltrate (e, f). Crypt architectural distortion (without any other evidence of inflammatory bowel disease) was seen in some patients in areas involved by mastocytosis (g). Scattered lymphocytes and plasma cells often accompanied the mast cell and eosinophil infiltrates (h). 



Figure 3 Spectrum of mast cell characteristics (morphological, histochemical and immunohistochemical). Mast cells exhibited a range of morphologic appearances that included (a) small, round resembling normal mast cells, (b) elongated or spindle-shaped, (c) plump or fusiform and (d) large, round cells with abundant pale to clear cytoplasmic, the latter a result of retraction artifact. The latter two patterns may be easily confused with histiocyte infiltrates. (e) Mast cell granules highlighted by Giemsa stain. (f, g) Immunohistochemical stains for mast cell tryptase and CD117, respectively. (h) Transmission electron micrograph of mast cells from a patient systemic mastocytosis showing numerous electron dense mast cell granules. 
and electron microscopy confirmed the mast cell infiltrate (Figure 3e-h). A CD68 stain, performed in two cases (due to initial morphologic impression of a histiocytic infiltrate) was positive in both.

\section{D816V Kit Mutation Analysis}

In four cases, tissue was available for D816V KIT mutation analysis and all demonstrated the mutation. In two of four patients the D816V KIT mutation was detected by direct sequencing while the remaining two cases were only demonstrated following enriched sequencing of the mutant alleles. ${ }^{25}$

\section{Clinical Follow-Up}

Clinical follow-up data are available for three patients. One patient was treated with imatinib and was clinically well but with continuing histological evidence of upper and lower gastrointestinal tract involvement at 29 months after diagnosis. A second patient was treated with $\mathrm{H} 1$ and $\mathrm{H} 2$ antihistamines, prednisolone and interferon- $\alpha$ with a good clinical response and normalization of serum tryptase levels and normalization of colonic and terminal ileal histology at 12 months. A third patient was treated with $\mathrm{H} 1$ and $\mathrm{H} 2$ antihistamines, prednisolone and interferon- $\alpha$ with good clinical response. However, subsequent discontinuation of prednisolone was associated with episodes of diarrhea and peripheral edema although the patient remains clinically stable at 44 months.

\section{Discussion}

In the absence of documented cutaneous lesions, the diagnosis of systemic mastocytosis may be easily missed due to its relative rarity and lack of awareness of its varied histopathological spectrum. An absence of skin lesions at the time of diagnosis has been reported in up to $40-50 \%$ of patients with systemic mastocytosis in some series ${ }^{26-29}$ (and $40 \%$ of the patients in our series). This emphasizes the need for pathologists to recognize systemic mastocytosis even when a clinical history of the characteristic skin lesions is not provided. The difficulty in appreciating the infiltrate as mast cells (as occurred initially in three of our cases) may compound the diagnostic challenge and lead to delay in the correct diagnosis.

Despite the frequency of gastrointestinal symptoms, the spectrum of histopathological findings in systemic mastocytosis remains incompletely characterized. Most publications are case reports and small series that have not been primarily focused histopathological features. An exception is a recent detailed study by Hahn and Hornick, ${ }^{14}$ which provided quantitative data on the mast cell infiltrate in six patients with systemic mastocytosis involving the gastrointestinal tract compared to other inflam- matory diseases of the gastrointestinal tract and normal controls. Our study aimed to further clarify and expand the description of the histopathologic changes in systemic mastocytosis and to highlight potential diagnostic pitfalls.

In our series, the most frequent presenting complaints were diarrhea, abdominal pain (cramping and dyspeptic), vomiting and weight loss. These findings are similar to those reported in other small series and case reports. ${ }^{2,5-11,13,14,16-18,21-23,26,30,31}$ Malabsorption, which occurred in two patients in our series is well described in systemic mastocytosis, ${ }^{2,5,7,9,10,16,23,30,31}$ occurring in $5-30 \%$ of patients. ${ }^{30,32}$ While all patients in our series were women, the literature indicates an equal sex distribution for systemic mastocytosis in general ${ }^{33}$ and for those cases with direct gastrointestinal involvement. $^{5-11,13,16-19,21-23,31}$

Endoscopically and grossly, the most frequent and distinctive finding in our series was that of mucosal nodularity (present in four of five patients). Such nodularity has been documented by others, both radiologically and endoscopically. ${ }^{2,6-8,18,19,23,34-38}$ Other nonspecific findings seen in this series and reported in the literature include erosions, loss of mucosal folds and friability. A substantial proportion of cases shows no obvious endoscopic or radiological abnormality. ${ }^{2}$

Histopathologically, all cases in our series showed mast cell infiltration of the lamina propria. This was usually diffuse with mast cells arranged in sheets and/or aggregates as previously described, ${ }^{14}$ and with frequent pericryptal accentuation. The literature shows considerable variation with respect to the presence and intensity of intestinal mast cell infiltrates in systemic mastocytosis. Several studies have reported an increase in lamina propria mast cells, ${ }^{7,8,11-14,16,22}$ while others have not. ${ }^{3,4,6,9,15,20}$ Such variation may reflect genuine differences among patients but may also be the result of differences in selection criteria, sampling variability and stains used to highlight mast cells. Many early studies used histochemical stains such as toluidine blue and Giemsa; these stains require the presence of intracytoplasmic mast cell granules and likely underestimate mast cell numbers compared to immunohistochemical stains such as mast cell tryptase and CD117, employed in more recent studies. Hahn and Hornick ${ }^{14}$ demonstrated qualitative and quantitative differences in mast cell infiltrates in systemic mastocytosis patients compared to those with other inflammatory gastrointestinal conditions and normal controls. Intestinal mast cell infiltrates exceeded 100h.p.f. in almost all cases (mean $\sim 200$ per h.p.f. compared to $\sim 30$ per h.p.f. in controls) and mast cells were arranged in aggregates or confluent sheets, features not seen in other inflammatory diseases or in normal controls. The true prevalence of intestinal mast cell infiltrates in systemic mastocytosis patients needs to be evaluated through prospective studies that include 
endoscopic biopsies of symptomatic patients with systemic mastocytosis.

Four cases in our series showed a dense eosinophil infiltrate in the lamina propria, sometimes obscuring the mast cell infiltrate, and leading to an erroneous diagnosis of eosinophilic colitis in one patient. This emphasizes the need for systemic mastocytosis to be considered in the differential diagnosis of eosinophil infiltrates in the gastrointestinal tract. Such heavy eosinophil infiltrates in gastrointestinal biopsies from systemic mastocytosis patients have documented by others. ${ }^{8,10,14,16,18}$ The use of special stains to highlight mast cells is invaluable in this setting as most other causes of mucosal eosinophil infiltrates (including eosinophilic gastroenteritis) are not associated with increased mast cells. ${ }^{14}$ An exception is parasitic infestation that may be associated with a prominence of both eosinophils and mast cells. However, the number of mast cells is generally lower than that seen in systemic mastocytosis and the mast cells occur singly rather than in aggregates or sheets. ${ }^{14}$

In our series, mast cells showed a morphologic spectrum that included systemic mastocytosis all round cells resembling normal mast cells, spindled or elongated cells, and larger plump to round cells resembling histiocytes (Figure $3 \mathrm{a}-\mathrm{d}$ ). The latter present a potential diagnostic pitfall as they may be easily mistaken for a histiocytic infiltrate, a problem compounded by mast cell immunoreactivity for CD68. Thus, systemic mastocytosis should be considered in the differential diagnosis of when confronted with histiocyte-like infiltrate in gastrointestinal biopsies.

Mucosal architectural distortion was evident in most cases in this series, and has been reported by others in both the small ${ }^{6-9,14,31,34,39}$ and large intestine. $^{7,14}$ The potential for misdiagnosis as inflammatory bowel disease (Crohn's disease or ulcerative colitis) therefore exists, particularly because colonoscopic findings in systemic mastocytosis may resemble inflammatory bowel disease. Indeed, three of five patients in our series had colonoscopic findings considered to be consistent with inflammatory bowel disease (although one had coexistent ulcerative colitis). The issue may be further complicated by the fact that the lamina propria infiltrate in systemic mastocytosis may include variable numbers of lymphocytes and plasma cells, ${ }^{6-8,10,14,23,31,39}$ and that inflammatory bowel disease may show a prominence of mast cells or eosinophils. ${ }^{40-42}$ A recent report of systemic mastocytosis mimicking Crohn's disease highlights the potential for misdiagnosis of these conditions. ${ }^{7}$ Features of active inflammatory bowel disease such as neutrophil cryptitis or crypt abscess are generally not a feature of systemic mastocytosis. ${ }^{14}$

A number of histochemical (Giemsa, toluidine blue and chloroacetate esterase) and immunohistochemical stains (mast cell tryptase, CD117) can be used to confirm the mast cell nature of the infiltrate. CD117 has the advantage of being able to detect degranulated mast cells. Although a CD117-positive round cell infiltrate may raise the possibility of an epithelioid GIST with mucosal involvement, immunoreactivity for mast cell tryptase and the absence of a mass lesion will rule out this possibility. Cell membrane immunoreactivity for CD25 is specific for systemic mastocytosis as this cell-surface molecule is expressed on neoplastic but not on non-neoplastic mast cells. CD25 expression on mast cells is readily distinguished from that on $\mathrm{T}$ cells because $\mathrm{T}$ cells have scant cytoplasm and exhibit stronger staining. ${ }^{14}$

More than $90 \%$ of patients with systemic mastocytosis exhibit the D816V KIT mutation in lesional tissue. ${ }^{1}$ Patients with this mutation are likely to be refractory to imatinib therapy. ${ }^{43}$ Data on the prevalence of this mutation in patients with direct gastrointestinal involvement by systemic mastocytosis or in gastrointestinal biopsies from such patients are lacking. In our series, all four patients with tissue available for molecular testing demonstrated the D816V KIT mutation. In two patients, the mutation was only detectable following enrichment of the mutant allele by incubation with the restriction enzyme BSMAI (which digests wild-type alleles). An enrichment procedure is often necessary in systemic mastocytosis because neoplastic mast cells may represent only a minor fraction of the cells present in biopsy samples. Enriched sequencing of mutant alleles, ${ }^{25}$ a quick and cost-effective technique is one of several sensitive techniques developed to overcome this limitation. ${ }^{25,44}$

In conclusion, this case series and literature review consolidates and expands current knowledge of the clinical, pathologic and molecular spectrum of systemic mastocytosis involving of the gastrointestinal tract. Pathologists should consider this condition when evaluating gastrointestinal biopsies from patients with a constellation of symptoms that include diarrhea, abdominal pain, vomiting and weight loss and when evaluating small bowel biopsies for malabsorption. Mucosal nodularity is a common and distinctive endoscopic and gross finding that should prompt consideration of systemic mastocytosis. Histologically, systemic mastocytosis is characterized by a spectrum of findings that may be readily diagnosed as mastocytosis or easily confused with other conditions such as inflammatory bowel disease, eosinophilic colitis or histiocytic infiltrates. Once the possibility of systemic mastocytosis is considered, the differential diagnosis is easily resolved with appropriate immunohistochemical stains. Sensitive methods allow for the detection of the characteristic D816V KIT mutation in paraffin sections from formalin-fixed endoscopic biopsies.

\section{Conflict of interest}

All authors declare no conflict of interest. 


\section{References}

1 Garcia-Montero AC, Jara-Acevedo M, Teodosio C, et al. KIT mutation in mast cells and other bone marrow hematopoietic cell lineages in systemic mast cell disorders: a prospective study of the Spanish Network on Mastocytosis (REMA) in a series of 113 patients. Blood 2006;108:2366-2372.

2 Jensen RT. Gastrointestinal abnormalities and involvement in systemic mastocytosis. Hematol Oncol Clin North Am 2000;14:579-622.

3 Siegert SI, Diebold J, Ludolph-Hauser D, et al. Are gastrointestinal mucosal mast cells increased in patients with systemic mastocytosis? Am J Clin Pathol 2004;122:560-565.

4 Achord JL, Langford $H$. The effect of cimetidine and propantheline on the symptoms of a patient with systemic mastocytosis. Am J Med 1980;69: 610-614.

5 Adler SN, Klein RA, Lyon DT. Bleeding after liver biopsy in a patient with systemic mastocytosis and malabsorption. J Clin Gastroenterol 1985;7:350-353.

6 Ammann RW, Vetter D, Deyhle P, et al. Gastrointestinal involvement in systemic mastocytosis. Gut 1976;17:107-112.

7 Bedeir A, Jukic DM, Wang L, et al. Systemic mastocytosis mimicking inflammatory bowel disease: a case report and discussion of gastrointestinal pathology in systemic mastocytosis. Am J Surg Pathol 2006;30:1478-1482.

8 Braverman DZ, Dollberg L, Shiner M. Clinical, histological, and electron microscopic study of mast cell disease of the small bowel. Am J Gastroenterol 1985;80:30-37.

9 Bredfeldt JE, O’Laughlin JC, Durham JB, et al. Malabsorption and gastric hyperacidity in systemic mastocytosis. Results of cimetidine therapy. Am J Gastroenterol 1980;74:133-137.

10 Broitman SA, McCray RS, May JC, et al. Mastocytosis and intestinal malabsorption. Am J Med 1970;48:382-389.

11 Ferguson J, Thompson RP, Greaves MW. Intestinal mucosal mast cells: enumeration in urticaria pigmentosa and systemic mastocytosis. $\mathrm{Br} \mathrm{J}$ Dermatol 1988;119:573-578.

12 Friedman BS, Metcalfe DD. Effects of tixocortol pivalate on gastrointestinal disease in systemic mastocytosis: a preliminary study. Clin Exp Allergy 1991;21:183-188.

13 Gasior-Chrzan B, Falk ES. Systemic mastocytosis treated with histamine $\mathrm{H} 1$ and $\mathrm{H} 2$ receptor antagonists. Dermatology 1992;184:149-152.

14 Hahn HP, Hornick JL. Immunoreactivity for CD25 in gastrointestinal mucosal mast cells is specific for systemic mastocytosis. Am J Surg Pathol 2007;31:1669-1676.

15 Hirschowitz BI, Groarke JF. Effect of cimetidine on gastric hypersecretion and diarrhea in systemic mastocytosis. Ann Intern Med 1979;90:769-771.

16 Jarnum S, Zachariae H. Mastocytosis (urticaria pigmentosa) of skin, stomach, and gut with malabsorption. Gut 1967;8:64-68.

17 Libel R, Biddle WL, Miner Jr PB, et al. Evaluation of anorectal physiology in patients with increased mast cells. Dig Dis Sci 1993;38:877-881.

18 Mahood JM, Harrington CI, Slater DN, et al. Forty years of diarrhoea in a patient with urticaria pigmentosa. Acta Derm Venereol 1982;62:264-265.
19 Quinn SF, Shaffer Jr HA, Willard MR, et al. Bull's-eye lesions: a new gastrointestinal presentation of mastocytosis. Gastrointest Radiol 1984;9:13-15.

20 Roberts PL, McDonald HB, Wells RF. Systemic mast cell disease in a patient with unusual gastrointestinal and pulmonary abnormalities. Am J Med 1968;45: 638-642.

21 Scolapio JS, Wolfe III J, Malavet P, et al. Endoscopic findings in systemic mastocytosis. Gastrointest Endosc 1996;44:608-610.

22 Tebbe B, Stavropoulos PG, Krasagakis K, et al. Cutaneous mastocytosis in adults. Evaluation of 14 patients with respect to systemic disease manifestations. Dermatology 1998;197:101-108.

23 Reisberg IR, Oyakawa S. Mastocytosis with malabsorption, myelofibrosis, and massive ascites. Am J Gastroenterol 1987;82:54-60.

24 Mickys U, Barakauskiene A, De Wolf-Peeters C, et al. Aggressive systemic mastocytosis complicated by protein-losing enteropathy. Dig Liver Dis 2007;39:693-697.

25 Tan A, Westerman D, McArthur GA, et al. Sensitive detection of KIT D816V in patients with mastocytosis. Clin Chem 2006;52:2250-2257.

26 Brunning RD, McKenna RW, Rosai J, et al. Systemic mastocytosis. Extracutaneous manifestations. Am J Surg Pathol 1983;7:425-438.

27 Travis WD, Li CY, Bergstralh EJ, et al. Systemic mast cell disease. Analysis of 58 cases and literature review. Medicine (Baltimore) 1988;67:345-368.

28 Webb TA, Li CY, Yam LT. Systemic mast cell disease: a clinical and hematopathologic study of 26 cases. Cancer 1982;49:927-938.

29 Yam LT, Chan CH, Li CY. Hepatic involvement in systemic mast cell disease. Am J Med 1986;80: 819-826.

30 Cherner JA, Jensen RT, Dubois A, et al. Gastrointestinal dysfunction in systemic mastocytosis. A prospective study. Gastroenterology 1988;95:657-667.

31 Dantzig PI. Tetany, malabsorption, and mastocytosis. Arch Intern Med 1975;135:1514-1518.

32 Horan RF, Austen KF. Systemic mastocytosis: retrospective review of a decade's clinical experience at the Brigham and Women's Hospital. J Invest Dermatol 1991;96:5S-13S; discussion 13S-14S.

33 Hartmann K, Henz BM. Mastocytosis: recent advances in defining the disease. Br J Dermatol 2001;144: 682-695.

34 Debray C, Leymarios J, Cerf M, et al. [Gastrointestinal mastocytosis. Report of a case and review of the literature]. Arch Fr Mal App Dig 1973;62:411-417.

35 Huang TY, Yam LT, Li CY. Radiological features of systemic mast-cell disease. Br J Radiol 1987;60:765-770.

36 Johnson AC, Johnson S, Lester PD, et al. Systemic mastocytosis and mastocytosis-like syndrome: radiologic features of gastrointestinal manifestations. South Med J 1988;81:729-733, 750.

37 Legman P, Sterin P, Vallee C, et al. [Colonic involvement in systemic mastocytosis (author's transl)]. Sem Hop 1982;58:1460-1463.

38 Mutter RD, Tannenbaum M, Ultmann JE. Systemic mast cell disease. Ann Intern Med 1963;59:887-906.

39 Bank S, Marks IN. Malabsorption in systemic mast cell disease. Gastroenterology 1963;45:535-549.

$40 \mathrm{He} \mathrm{SH}$. Key role of mast cells and their major secretory products in inflammatory bowel disease. World J Gastroenterol 2004;10:309-318. 
41 King T, Biddle W, Bhatia P, et al. Colonic mucosal mast cell distribution at line of demarcation of active ulcerative colitis. Dig Dis Sci 1992;37:490-495.

42 Miner Jr PB. The role of the mast cell in clinical gastrointestinal disease with special reference to systemic mastocytosis. J Invest Dermatol 1991;96: 40S-43S; discussion 43S-44S.
43 Patnaik MM, Rindos M, Kouides PA, et al. Systemic mastocytosis: A concise clinical and laboratory review. Arch Pathol Lab Med 2007;131:784-791.

44 Sotlar K, Escribano L, Landt O, et al. One-step detection of c-kit point mutations using peptide nucleic acidmediated polymerase chain reaction clamping and hybridization probes. Am J Pathol 2003;162:737-746. 